a. Reports on a project, program, or research underway or recently completed dealing with a topic relevant to academic librarianship. Footnotes should be minimal and charts or tables avoided. These reports may be preliminary descriptions of programs or research to be published formally at a later date in library literature (e.g., "Undergraduate Term Paper Citations in Two Colleges and Two Universities: A Comparison," January 1990).

b. Reports on a recent conference or workshop of interest to academic or research librarians (e.g., "Middle States Association Makes a Commitment to BI," December 1989).

c. Reasoned and informed speculation or comment on a relevant topic, especially if solicited by the editor or an official ACRL group (e.g., "The Future of Reference II," October 1989).

d. State-of-the-art reports on a relevant topic (e.g., "Installing a Local Area Compact Disk Network," December 1989).

e. Standards, guidelines, or recommendations of an ACRL committee or other official ACRL group (e.g., "Standards for University Libraries," September 1989).

\section{Manuscript}

Authors should submit two copies, doublespaced, following either the Chicago Manual of Style or Turabian.

Printing output to be avoided: low-resolution dot matrix, proportional spacing, oversize type, and hyphenated word breaks.

Manuscripts may also be submitted in electronic format (hard copy is still required) either:

a. via ALANET, to ALA0306; or

b. in a text file on an IBM-compatible diskette, preferably in Xywrite III+ or in an ASCII file.

\section{$V$. Requests for Donations}

$C \mho R L$ News may occasionally print requests for the donation of books or materials to libraries, especially foreign libraries, which have suffered extensive loss through fire, hurricane, or other natural disaster. Other libraries soliciting contributions for other reasons will be referred to the rates for classified advertising in C $\mho R L N e w s$.

Editor's note: These guidelines were adopted by the C\&RL News Editorial Board at the Denver Midwinter Meeting on January 25, 1982.

\title{
Suggestions for editors
}

\author{
By J. C. Bennett \\ Assistant Professor of Library Science \\ Eastern New Mexico University
}

\section{The other side of the manuscript.}

\section{A} lthough most librarians are not formally required to publish written work, a great many-particularly in academic libraries - will consider doing so at some point in their careers. Many library science journals exist for the purpose, and they seem typical of periodicals as a whole. Almost every journal contains either "guidelines for authors" or "instructions to authors" or the like. This usually consists of a page in each issue ad- dressed to prospective authors, detailing the style submitted manuscripts should take, the length and form preferred, and other miscellaneous information. Often authors are nastily told that submissions that do not fit the guidelines will be returned unread.

The relationship between author and editor should be one of mutual respect. If authors are bluntly directed to follow some conventions and 


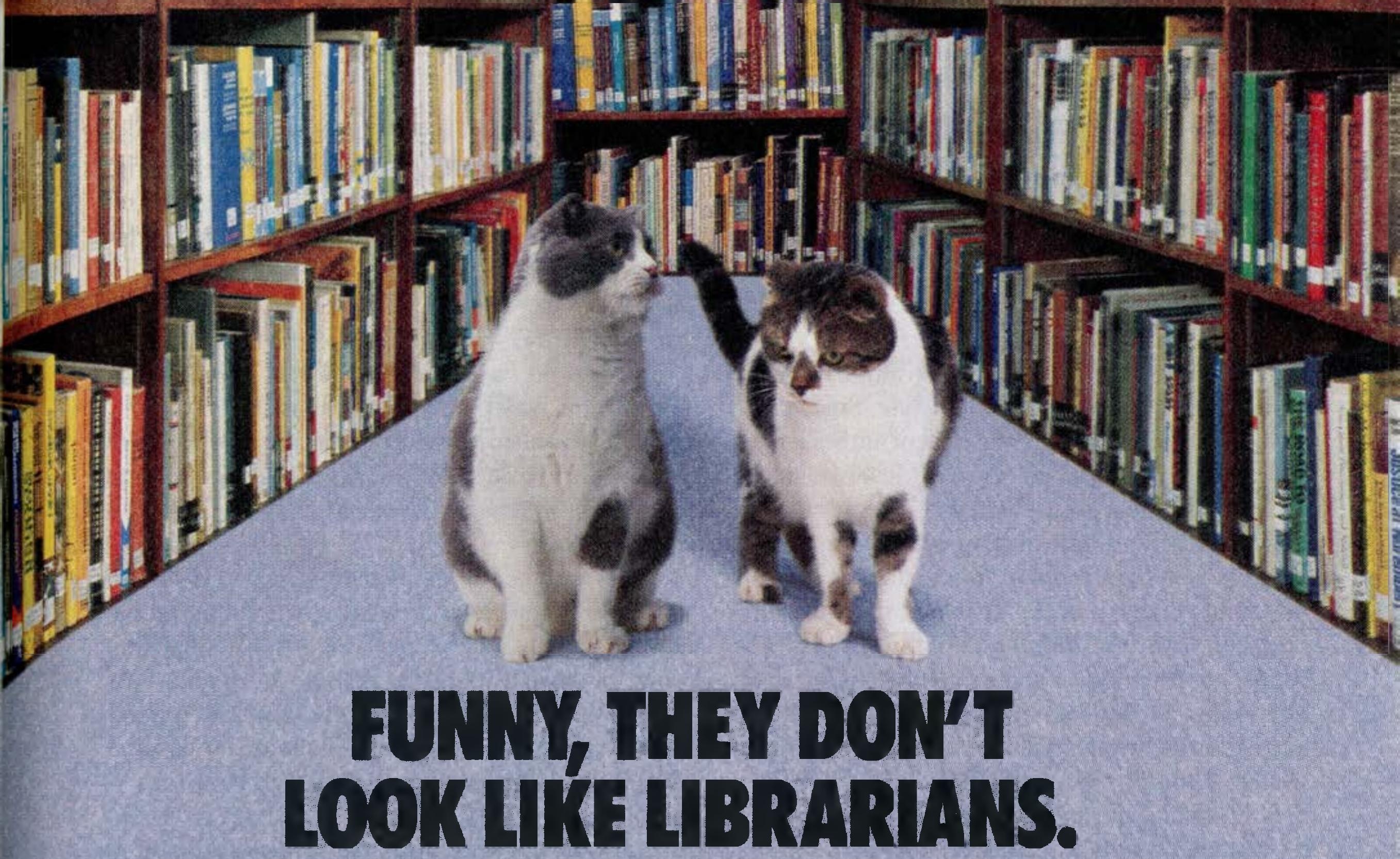

\section{BUT THIS COUPLE OF CATS REPRESFIIS A COMPAY THAT STAFS THE MOST INHOUATVE LBRARIAUS - RALY TO HALP WOU BULL THE BEST COLLCTIOUS POSSIBLE.}

From sales to marketing to customer service, our librarians bring their expertise and insight to every facet of Baker \& Taylor Books. That's especially important when it comes to the challenging task of collection development. Let Baker \& Taylor Books' librarians help make your job a lot easier through these time and effort-saving programs:

\section{BUILDING COMPREHENSIVE COLLECIONS.}

Our Approval Program offers the most sophisticated collection development system in the industry. It includes specialized services like customized profiling to make sure every automatic shipment of new titles you get meets your library's requirements. Periodic reports, free freight and a choice of discount plans are other valuable features of our Approval Program.

\section{BUILDING STANDING ORDER COLLECTIONS.}

Our Continuation Service is a standing order program that makes it easier than ever to bring order and control to your serial collections. Offering a comprehensive database of over
25,000 titles, Continuation Service means you can order everything from one source - Baker \& Taylor Books.

\section{INTRODUCING}

OPENING DAY COLLECTION SERVICES.

There's nothing we won't do to help you through the enormous complexity of building a new library or the challenge of expanding a collection. Indeed, our new Opening Day Collection Services include everything: planning and selecting, cataloging and processing, packing and shipping. If you'd like, we'll put the books right on your shelves.

\section{BUILDING PAPERBACK COLLECIONS.}

We get you hot paperback titles quickly and easily through our Paperback Parade Service. We do it by offering a broad range of ordering plans which are geared to different age groups, types of libraries and popular subjects. All you have to do is sign up for a predetermined number of titles at one set price and we'll automatically ship a new selection to you each month

As you can see, with so many innovative librarians working for us, we've got collection development down to a science. To take advantage of these outstanding programs, call the

Baker \& Taylor Books division nearest you today 
not others to make editors' jobs easier, it is reasonable to ask that editors also do what they can to lighten authors' tasks. A list of suggestions for journal editors follows. It is hoped that editors will take these seriously. The present lack of discipline and standardization discourages many who might otherwise be very successful writers.

1. Do not require that the first submission of a manuscript be in any particular style. Since many styles exist this wastes a great deal of authors' time. Any recognized style will allow review of a manuscript; if it is clearly unacceptable, the author does not wish to spend time putting it into your particular style. You may also lose your chance at publishing noteworthy pieces. This is especially pronounced if your journal has a high rejection rate. Above all, do not give special instructions that do not follow recognized styles; if a manuscript is accepted, its author will be more than happy to change it to any style you wish.

2. Put in your guidelines a statement on the topics you wish manuscripts to address. This must be as specific as possible. It will lighten your load, as well, for you will spend less time mailing back utterly unsuitable manuscripts. Do not tell authors to read back issues to find out what you require; since budgets are shrinking many libraries have dropped their subscriptions to your journal, and authors will often have only a photocopy of your guidelines to refer to.
3. Comment on each manuscript you reject. If your guidelines contain a detailed statement of the topic(s) you desire articles on, you need only send authors of unsuitable submissions a copy of guidelines with a note stating the particular unfitness. The following excuses for rejection are unacceptable:

a. "We reject a lot of manuscripts." This does not tell authors why theirs are unsuitable.

b. "The tone (or style or format) is not what we're looking for." Unless you suggest the author rewrite and resubmit the piece, you have not given reasons for rejection.

c. "We do not agree with your logic." If you do not offer sound logical reasons which negate the author's argument, this excuse is not an appropriate point of departure. If you wish to reject an article simply because you don't like its conclusions, you should consult with the ALA Intellectual Freedom Committee for guidance. In such a case any conscientious author will contact that committee to complain about you. Remember, if you cannot find the time to explain your reasons to each rejected author, you do not have time to be an editor.

4. If you wish an author to rewrite and resubmit a piece, tell exactly what you would like altered or added. Too many authors have been frustrated by editors who simply mail them copies of reviewers' reports, for these often contradict each other or are too vague to be used as guides.

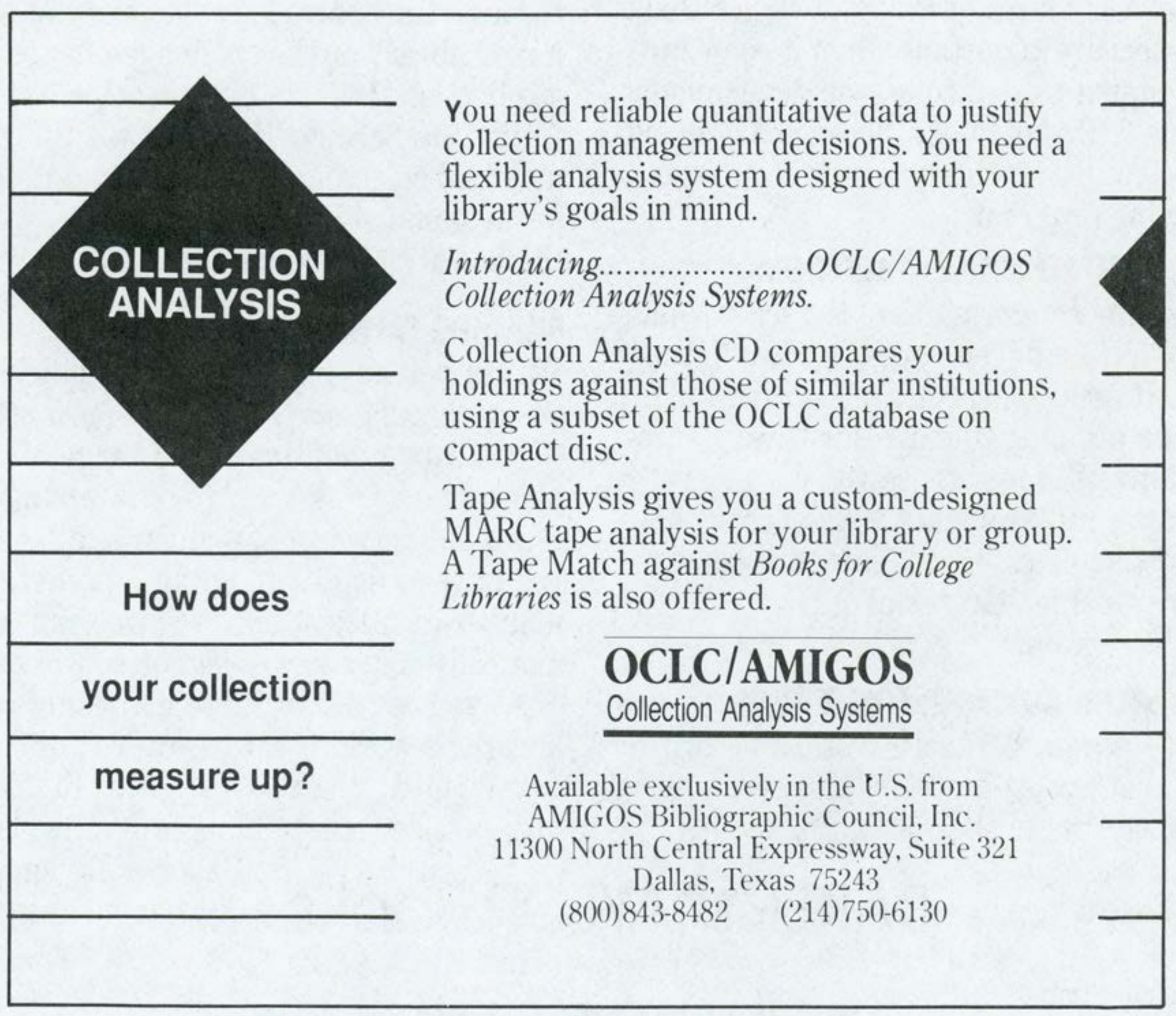


5. Do not ask that an author submit the original copy of a manuscript. It is perfectly acceptable to ask authors to state that their articles are not under consideration by other publications, but to require that a manuscript be retyped when you reject it (since you will have mangled its corners or left coffee stains on its pages) is unconscionable. In your position you probably have a computer or word processor, but not every writer can afford one.

6. Be fair about time limits. If it has taken you months to review and accept a manuscript, do not expect its author to return proofs to you within 72 hours of receipt. Also authors should realize that you have little control over your referees, but it should not take a non-refereed periodical more than six weeks to review a manuscript nor a refereed one longer than four months. The approximate time yours will take should be listed in your guidelines; if delays occur after submission, notify the author of them.

7. Enjoy your work. Editing is an honor, not a right, and deserves the best you can give it. Authors need you, and you need them.

\section{㧒 News from the Field}

\section{Acquisitions}

- The Louisiana State University Libraries, Baton Rouge, have recently acquired an important group of 19th-century manuscript materials. The papers, consisting of more than 3,000 manuscript items, document the activities of members of the Stirling, Turnbull, Joyce, Lobdell, and Allain Families. Covering nearly the entire 19th century, the materials document the commerce and trade in which these families were engaged, the operations of their numerous plantations, including the buying and selling of slaves, and the personal matters of the various family members. This collection complements the already extensive holdings in the Louisiana and Lower Mississippi Valley Collections at LSU that document not only the very same families, but the entire West Florida area. The manuscripts fall into four main family groupings: the Lewis Stirling Family Papers, which relate to the Civil War career of Lewis Stirling and the life of the family during reconstruction; the TurnbullJoyce Partnership and estate records, which document the trading activities of John Joyce and his partner John Turnbull, including accounts with individual Indian traders on the Louisiana-Mississippi frontier, and bills and receipts for trade goods; the Lobdell Family Papers, which trace the arrival John Lobdell in Louisiana during the 1820s and his subsequent participation in the legal, political, and economic life of the state, including his leadership in the Masonic Lodge; the Allain Family Papers, which consist of personal and family letters as well as the business and financial records of V. F. and Sarah Allain. The acquisition of these important papers was made possible through the generous support of the Friends of the LSU Library, members of the Stirling family, the West Feliciana Historical Society, and other generous anonymous benefactors.

- TheSt. Louis Mercantile Library Association has acquired an important new collection received in recent months from the Transportation Research Forum (TRF) Foundation, of Washington, D.C. Most notable among the titles received in the TRF Foundation's gift is a nearly complete run from the early 1870s to the present of The Official Guide of the Railways and Steam Navigation Lines of the United States, Porto Rico, Canada, Mexico and Cuba, known to generations of its users simply as The Official Guide. Long one of the most important railroad periodicals, The Official Guide and various related predecessor titles has published each month since June 1868 the most complete available compilation of the passenger and freight service timetables of all railroads in the United States, and later, all of North America. Route and service maps and advertisements, listings of services offered, station lists, and rosters of principal managers and officers are also featured. Long runs of the Guide are rare, and nearly complete runs such as that received from the TRF Foundation exist in only a few repositories. With the Guides came other important titles of high research value. Notable is a complete run of The Pocket List of Railroad Officials, which has four times yearly 